\title{
Commentary: Minimally invasive thoracic surgery lobectomy: Truth versus hype
}

\author{
Raja M. Flores, MD
}

\footnotetext{
From the Department of Thoracic Surgery, Icahn School of Medicine at Mount Sinai, Mount Sinai Health System, New York, NY

Disclosures: Author has nothing to disclose with regard to commercial support

Received for publication Sept 12, 2019; revisions received Sept 12, 2019; accepted for publication Sept 13, 2019; available ahead of print Oct 15, 2019.

Address for reprints: Raja M. Flores, MD, Department of Thoracic Surgery, Mount Sinai Health System, Icahn School of Medicine at Mount Sinai, One Gustave L. Levy Place, Box 1023, New York, NY 10029 (E-mail: raja.flores@mountsinai.org).

J Thorac Cardiovasc Surg 2020;159:295-6

$0022-5223 / \$ 36.00$

Copyright (c) 2019 by The American Association for Thoracic Surgery

https://doi.org/10.1016/j.jtcvs.2019.09.017
}

Minimally invasive thoracic surgery lobectomy (videoassisted thoracic surgery [VATS] or robot-assisted thoracoscopic surgery [RATS]) is believed to provide smaller incisions, less pain, and quicker recovery. Many published studies demonstrate a 1-day shorter length of stay, less pain medication required, and similar oncologic outcomes compared with thoracotomy. So why not use minimally invasive thoracic surgery?

The literature in favor of minimally invasive thoracic surgery is riddled with selection and publication biases. Studies highlighting favorable VATS outcomes are frequently published but miss the true outcomes because of surgeon bias, flawed data-gathering, and study methodology. For example, 2 large VATS studies from our own institution missed a dozen life-altering and life-ending intraoperative complications that were subsequently published in a later study. ${ }^{1-3}$ A multiinstitutional European study identified 46 such complications never published in previous studies from the involved institutions. ${ }^{4}$ Even the Society of Thoracic Surgeons database misses these specific complications, thereby ineffectively warning surgeons of potential dangers while touting its benefits.

Minimally invasive incisions are smaller but not that much smaller. Thoracotomies today are not as large as in the past due to staplers. Some thoracotomies are even the same size as VATS or RATS incisions used to retrieve the lobectomy specimens from the chest. Pain is less but not that much less. Post-thoracotomy pain syndrome still occurs in both VATS and RATS. A large study from Memorial Sloan Kettering Cancer Center showed no difference in quality of life, and an enhanced recovery after surgery study showed no difference in length of stay. ${ }^{6,7}$ Nodal retrieval is related to surgeon effort, not the technique used. The hidden dangers of VATS and RATS to the unsuspecting thoracic surgeon operating on a difficult body habitus can be life-threatening to the patient. These but you.

\section{References}

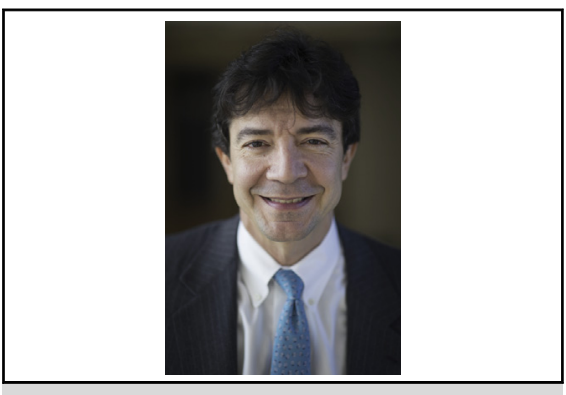

Raja M. Flores, MD

Central Message

The minor advantages of minimally invasive thoracic surgery are no substitute for good surgical judgment.

See Article page 284 .

dangers are also present in open procedures, but the consequences are even greater with limited access. The big picture should consider the risk of an unplanned pneumonectomy for 1 patient versus a day less in the hospital for a hundred others.

I have been an advocate for minimally invasive surgery more than 25 years now. I will continue to do so but not as fervently as I once did. Major complications are greatly underreported, and benefits are overexaggerated. Caution in every surgery is a must, and smaller incisions can never replace good judgment.

We all want what's best for our patients, but subconsciously, academic notoriety, financial gain, competition for patient referrals, bravado, and a $\$ 63$ billion-dollar robotic company can influence our practice. We must be aware of these influences to monitor ourselves and ensure that we provide optimal care. Complications happen. It's part of the job. As a surgeon you need to be able to look yourself in the mirror and ask "did I do the right thing for this patient?" In the end no one will ever know...

1. Flores RM, Park BJ, Dycoco J, Aronova A, Hirth Y, Rizk NP, et al. Lobectomy by video-assisted thoracic surgery (VATS) versus thoracotomy for lung cancer. J Thorac Cardiovasc Surg. 2009;138:11-8.

2. Flores RM, Ihekweazu UN, Rizk N, Dycoco J, Bains MS, Downey RJ, et al Patterns of recurrence and incidence of second primary tumors after lobectomy by means of video-assisted thoracoscopic surgery (VATS) versus thoracotomy for lung cancer. J Thorac Cardiovasc Surg. 2011;141:59-64. 
3. Flores RM, Ihekweazu U, Dycoco J, Rizk NP, Rusch VW, Bains MS, et al. Video-assisted thoracoscopic surgery (VATS) lobectomy: catastrophic intraoperative complications. J Thorac Cardiovasc Surg. 2011;142:1412-7.

4. Decaluwe H, Petersen RH, Hansen H, Piwkowski C, Augustin F, Brunelli A, et al. Major intraoperative complications during video-assisted thoracoscopic anatomical lung resections: an intention-to-treat analysis. Eur J Cardiothorac Surg. 2015;48:588-98

5. Paul S, Altorki NK, Sheng S, Lee PC, Harpole DH, Onaitis MW, et al. Thoracoscopic lobectomy is associated with lower morbidity than open lobectomy: a propensity-matched analysis from the STS database. J Thorac Cardiovasc Surg. 2010;139:366-78.

6. Rizk NP, Ghanie A, Hsu M, Bains MS, Downey RJ, Sarkaria IS, et al. A prospective trial comparing pain and quality of life measures after anatomic lung resection using thoracoscopy or thoracotomy. Ann Thorac Surg. 2014;98:1160-6.

7. Krebs ED, Mehaffey JH, Sarosiek BM, Blank RS, Lau CL, Martin LW. Is less really more? Reexamining video-assisted thoracoscopic versus open lobectomy in the setting of an enhanced recovery protocol. J Thorac Cardiovasc Surg. 2020;159:284-94.e1. 